\title{
DIFFERENCES BETWEEN THE OUTER AND INNER STRUCTURE OF THE SHORT-TOED TREECREEPER'S (CERTHIA BRACHYDACTYLA BREHM, 1820) NEST IN AN URBAN AREA
}

\section{RAPID COMMUNICATION}

\author{
Corrado Battisti ${ }^{a}$, b*and Giuliano Fanelli ${ }^{\mathrm{c}}$
}

\author{
aTorre Flavia' LTER (Long Term Ecological Research) Station, Protected Areas - Regional Park Service, Città Metropolitana di \\ Roma Capitale, viale G. Ribotta, 41, 00144 Rome, Italy \\ bDipartimento di Scienze - Università di Roma III, viale G. Marconi, 446, 00146 Rome, Italy \\ ORCID: http://orcid.org/0000-0002-2621-3659 \\ 'Dipartimento di Biologia, Seconda Università di Roma Tor Vergata, Via della Ricerca Scientifica, 00133 Rome, Italy \\ *Corresponding author. Email: c.battisti@cittametropolitanaroma.gov.it
}

Article history
Received: 2 May 2021;
accepted: 16 September 2021
Keywords:
Nest composition; pine
needles; twigs; feathers;
ornamental plants

\begin{abstract}
We reported the first available data on the fine-grained structure of the short-toed treecreeper's (Certhia brachydactyla Brehm, 1820) nest located in an urban park of Rome (central Italy). The outer structure was characterized by a high percentage of conifer (Pinus pinea) needles, which are significantly longer than other branches and twigs. Pine needles are widely available in urban parks, and being more flexible and easily detachable, may contribute to the support of the outer nest structure provided by other linear components (i.e., twigs/branches). Moreover, their aromatic terpenes may control nest parasites. In contrast, the internal cup lining was composed of a very light and heterogeneous set of components (bird feathers of at least one synanthropic bird species: Streptopelia decaocto), vegetable fluff, grass leaves, shrubs and trees, moss, sand, dust, and plant roots, i.e., all the materials largely used in bird nests because of their insulative qualities and thermoregulation functions. Although the internal cup lining was more heterogeneous in composition, the total weight of the outer nest was significantly heavier ( $>65 \%$ on the total nest weight).
\end{abstract}

\section{INTRODUCTION}

Although it has been recognized that bird nests are multifunctional structures fulfilling ecological, behavioural and evolutionary functions that are far more sophisticated than previously realized (Mainwaring et al. 2014; Deeming and Mainwaring 2015), studies on speciesspecific nest structures of some species in terms of fine-grained composition are still scanty (e.g., Winkler and Sheldon 1993; Hansell 2000; Merlino et al. 2018). As reported by Biddle et al. (2018a), nest size is known only for about 300 species, and the materials used for nest building have been quantified for less than 20 species (see also Deeming 2013; Deeming and Mainwaring 2015; Taberner Cerezo and Deeming 2016; Briggs and Deeming 2016; further examples at single species level in Navarro et al. 2010; Battisti and Fanelli 2021).

Treecreepers (Certhia spp.) represent a group of forest secondary cavity nesters (Newton 1994) preferring small tree holes excavated by woodpeckers or left by dead branches (Cramp 1988; Basile et al. 2016), and also occurring in nest boxes (e.g., Kuitunen and Aleknonis 1992; Robles et al. 2012; Deeming et al. 2017). However, excluding historical notes (e.g., Tyler 1914), analyses of the fine-grained structure and composition of the treecreeper's nests has been reported only in general terms (Cramp and Perrins 1993), as highlighted by Goodall et al. (2019).

The short-toed treecreeper (Certhia brachydactyla Brehm, 1820), a resident and specialist small Western Palearctic passerine species usually found in oak or mixed-deciduous forests (with prevalence of oaks, Quercus spp.), has recently colonised urban parks (Snell et al. 2020). This species frequently uses artificial nest boxes both during and outside the breeding season (Mainwaring 2011; for Italy: see Mascara et al. 2011). Thus, some authors (e.g., Harrap 1996) have provided a qualitative assessment of its nest composition specifying such materials as conifer needles, grass, bark, plant fibres, cloth, and paper, lined with feathers, hair, down rootlets, moss and lichens.

In this note we report a quantitative evaluation of the fine-grained structure and composition of a single nest of the short-toed treecreeper (Certhia brachydactyla) located in an urban park. To our knowledge, these are the first data on this topic available for this secondary hole-nesting species. 


\section{MATERIALS AND METHODS}

We sampled the treecreeper's (Certhia brachydactyla) nest, which had been attributed to this species based on direct observations, in April, 2021. The nest was put in an artificial nest box $(12 \times 12 \times 14 \mathrm{~cm})$, which was placed on a non-native Melia azedarach tree (diameter at breast height: $46 \mathrm{~cm}$ ) growing in a suburban residential park in the western sector of Rome (via dei Carafa, central Italy; $60 \mathrm{~m}$ a.s.1.; 41 $\left.{ }^{\circ} 51^{\prime} 51.0^{\prime \prime} \mathrm{N}, 12^{\circ} 24^{\prime} 59.0^{\prime \prime} \mathrm{E}\right)$ at a height of $3.5 \mathrm{~m}$ above ground. In the immediate surroundings of the nest tree, there was a large number of non-native ornamental coniferous (Cedrus libani, C. atlantica, Pinus pinea) and deciduous (Ailanthus altissima, Celtis australis, Eucalyptus sp., Prunus sp., Malus sp.) trees surrounded with hedges (Laurus nobilis, Hedera helix, Pittosporum tobira). The herbaceous layer was mainly composed of Urtica membranacea, Geraniun molle, Perietaria judaica, Sonchus asper. In the vicinity, there are two nature reserves ("Valle dei Casali" and "Tenuta dei Massimi") characterized by a typical landscape mosaic of Campagna Romana (Quercus suber wood fragments) with synanthropic and ecotonal habitats (see Fanelli 1998; Fanelli et al. 2007; Battisti and Mandolini 2018 for details).

To characterize the nest structure and composition, we distinguished two sectors: the internal cup lining (nest chamber) and the peripheral sector (the outer nest, surrounding the nest chamber). The entire nest was deconstructed and disassembled, different materials being separated in categories so as to determine the nest composition and weight (in grams; using a professional scale Sartorius analytic; error $\pm 0.00001 \mathrm{~g}$ ). As to the outer nest, all linear components (woody branches and twigs vs. conifer needles) were also measured in length (in $\mathrm{cm}$ ), using a professional calliper (Vernier LS PRO).

We obtained relative weight frequencies (Fr) for all material categories and compared the total material frequency for both the outer nest and the internal cup lining using an $\chi^{2}$ test. The average length was compared between sectors using a Mann-Whitney U test (Dytham 2011). To test for difference in the frequency distribution of length measurements of both woody twigs and conifer needles, we used the Kolmogorov-Smirnov test. Alpha level was set at 0.05 . We used the PAST 4.01 software for statistical analyses (Hammer et al. 2001).

\section{RESULTS}

The outer part of the nest was exclusively composed of linear components (branches/twigs of Hedera helix and Rosacea ind.; Pinus pinea needles). The internal cup consisted of (in decreasing order of weight) vegetable fluff, dust and sand, grass leaves (Graminaceae), bird feathers (probably, of Streptopelia decaocto and others undetermined), plant roots, leaves (Quercus sp., Hedera helix), grass sheaths (Graminaceae), and moss (Rhynchostegium cfr. murale; Table 1). Although the internal cup lining was more heterogeneous in composition, the total weight of the outer nest was significantly heavier (13.505 vs. $6.688 \mathrm{~g} ; \chi^{2}=7.18, p<0.05$; Table 1).

As to linear components of the outer nest, we counted 234 items (mean length: $65.88 \mathrm{~mm} \pm 32.30$ (range: $12-192), 42$ of which were conifer needles $(17.9 \%$ of the total linear components; mean length: $88.24 \mathrm{~mm} \pm$ 33.50 ; range: $17-182)$ and 192 woody twigs $(60.99 \mathrm{~mm}$ \pm 29.97 ; range: $12-192)$. Pine needles were significantly longer than twigs (pine needles $v s$. tree twigs: $\mathrm{U}=2000$, $\mathrm{Z}=5.115, p<0.001$; U Mann-Whitney test; Figure 1). The abundance frequency distribution of pine needles $v s$. tree twigs/branches shows a significant difference $(\mathrm{D}=0.44, p>0.01$, Kolmogorov-Smirnov test), with the modal class of pine needles being longer than that of twigs/branches (Figure 2).

\section{DISCUSSION}

In our exploratory study we observed a marked difference between the two sectors of the short-toed treecreeper's nest. The internal cup lining was lighter but more heterogeneous in composition than the outer nest, which represented the major part of the total nest weight $(>65 \%)$.

Structural properties of different bird nest sectors vary according to their specific functions. Therefore, the nest-building materials used in the parts of the nest

Table 1. Composition of the Short-toed Treecreeper' nest in an urban park, subdivided into the outer nest and the internal cup lining. Weight (with frequency, in g) of all material categories is presented. (*) including twigs of Hedera helix and Rosacea ind.

\begin{tabular}{|c|c|c|c|}
\hline & Components & Weight $(\mathrm{g})$ & Fr \\
\hline$\stackrel{\bar{\Xi}}{\overrightarrow{0}}$ & $\begin{array}{l}\text { Linear components (branches/twigs* } \\
\text { and Pinus pinea needles) }\end{array}$ & 13.505 & 0.667 \\
\hline \multirow{8}{*}{ 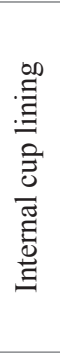 } & Vegetable fluff & 2.518 & 0.124 \\
\hline & Dust and sand & 1.949 & 0.096 \\
\hline & Leaves of grasses (Graminaceae) & 0.911 & 0.045 \\
\hline & Bird feathers & 0.505 & 0.025 \\
\hline & Roots & 0.363 & 0.018 \\
\hline & Leaves (Quercus sp., Hedera helix) & 0.317 & 0.016 \\
\hline & Sheaths of grasses (Graminaceae) & 0.125 & 0.006 \\
\hline & Moss (Rhynchostegium cfr. murale) & 0.052 & 0.003 \\
\hline & Total & 20.193 & 1 \\
\hline
\end{tabular}




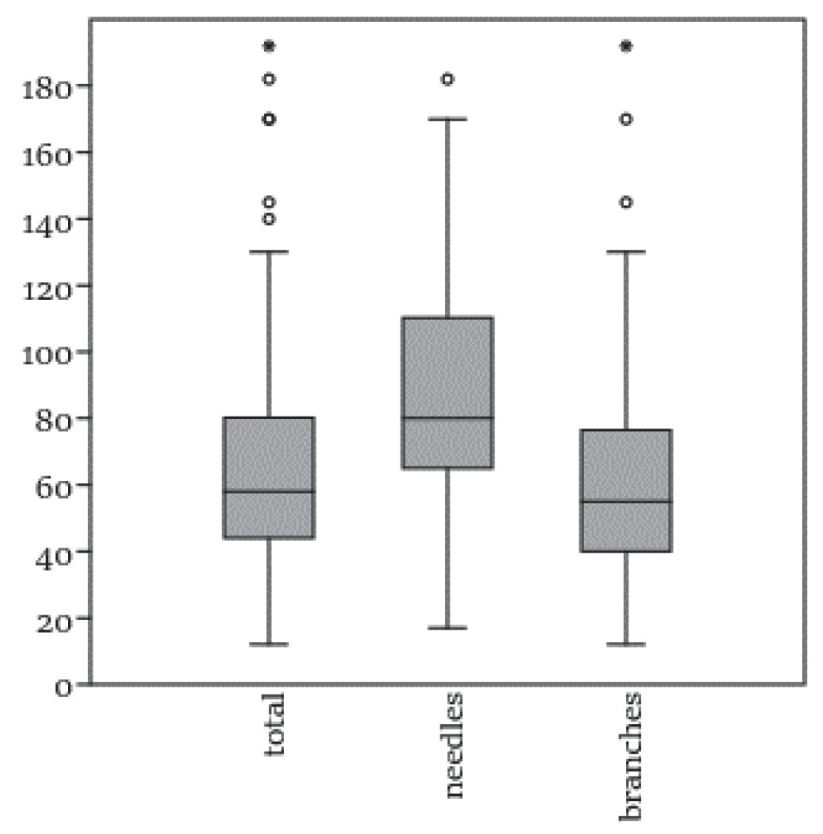

Figure 1. Mean length of linear components (box-whisker plot: total, $\mathrm{N}=234$; pine needles: $\mathrm{N}=43$; twigs and branches: $\mathrm{N}=$ 192 ) in the outer nest of the Short-toed Treecreeper (Certhia brachydactyla). For each sample, the 25-75 percent quartiles were drawn using a box. Horizontal line inside the box: median values. Short horizontal lines ("whiskers"): minimal and maximal values. Points represent the outliers.

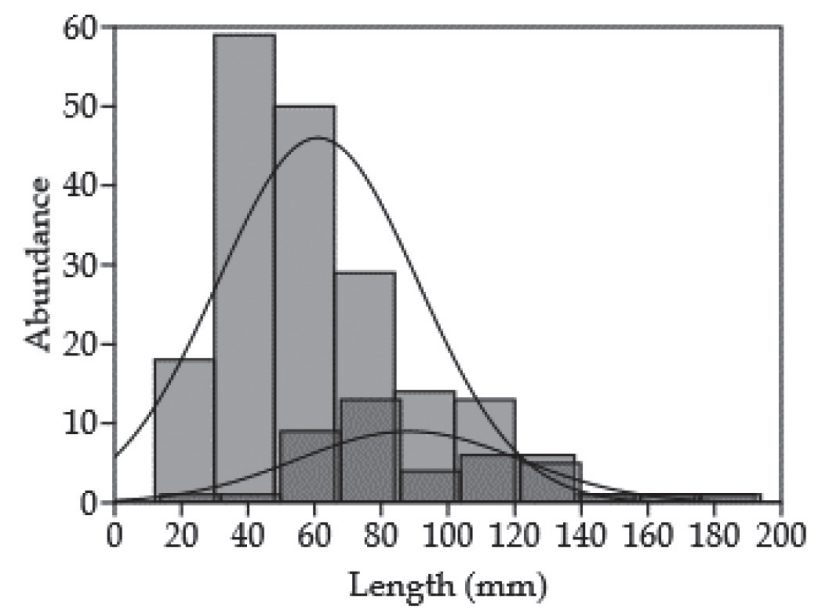

Figure 2. Frequency distribution in abundance (=n. items) for different length categories (in $\mathrm{mm}$ ) and hump-shaped curves (Kolmogorov-Smirnov test for equal distributions). Light grey: branches and twigs; dark grey: pine (Pinus pinea) needles.

that need most support (the outer sector) are thicker and stronger than those used in the internal cup lining (see Biddle et al. 2018b). Here, in the outer nest, we recorded mainly twigs, branches and conifer (Pinus pinea) needles, which are widely used in bird nests (e.g., Erickson and Martinez-Vargas 1973; Csada and Brigham 1994; Quilodrán et al. 2012; Reynolds et al. 2019; for the congeneric Certhia familiaris Linnaeus, 1758: see Goodall et al. 2019; for other cavity nesters: Gelis and Martinez 2000). Due to their shape and size, pine needles are suitable for fulfilling the structural support function of the outer nest (Goodall et al. 2019), in addition to other linear components (i.e., twice and branches). Indeed, we found that conifer needles were significantly longer than the twigs. Moreover, they are more flexible and easily detachable from plants (for ductility and elasto-plastic properties of conifer needles, see Howard 1973; Jové-Sandoval et al. 2018). The additional function of pine needles as aromatic fragments can be inferred due to their richness in terpenes (Pires et al. 2012), such as limonene, a compound known to reduce fleas and ticks in domestic animals (Macchioni et al. 2002; Hinkle 2010).

In South European urban environments, conifer needles are readily available because these trees are widely cultivated for ornamental purposes. In addition, almost all components of the outer nest are from the ornamental plants grown in urban gardens (as Rosaceae ind. and Hedera helix), which is in line with the observations of other researchers stating that the composition of a bird nest may reflect the availability of resources, habitat types and species of plants growing in the vicinity (Lambrecths et al. 2017; Reynolds et al. 2019).

As opposed to the structural function of the external part, the internal cup lining appears to be very light and heterogeneous in composition, which includes feathers of at least one synanthropic bird species (Streptopelia decaocto), vegetable fluff, leaves of grass, shrubs and trees, moss, sand, dust, and roots, all the materials largely used in bird nests because of their insulation qualities and thermoregulation functions, as well as those used for the maintenance of stable temperatures in the incubation chamber (Lombardo et al. 1995; Hansell 2000; Goodfellow 2011).

To our knowledge, data about the fine-grained structure and composition of the short-toed treecreeper's nest have not been published previously. However, although the number of items analysed in our study was representatively large, this note reports only the data obtained from a focal nest in an urban context. Since this nest was located in a peculiar context (urban park with a high plant diversity), its structure cannot be considered to be representative of the entire species' nests. Therefore, to provide a more general overview of the short-toed treecreeper's nest structure, further research using a larger size sample has to be conducted.

\section{ACKNOWLEDGMENTS}

Fulvio Fraticelli and Marzio Zapparoli added useful comments and suggestions. Laima Monkienè and Birute Jankauskiene provided a further improvement of English style/language and editing. 


\section{COMPETING INTEREST}

The authors declare that they have no competing interest.

\section{DISCLOSURE STATEMENT}

No potential conflict of interest was reported by the authors.

\section{REFERENCES}

Basile, M., F. Valerio, R. Balestrieri, M. Posillico, R. Bucci, T. Altea, B. De Cinti, and G. Matteucci. 2016. Patchiness of forest landscape can predict species distribution better than abundance: the case of a forest-dwelling passerine, the short-toed treecreeper, in central Italy. Peer Journal 4: e2398.

Battisti, C., and G. Fanelli. 2021. A fine-grained analysis of a Monk parakeet (Myiopsitta monachus) nest suggests a nonhomogeneous internal structure. Zoology and Ecology 31 (1): 60-63. https://doi.org/10.35513/21658005.2021.1.6

Battisti, C., and R. Mandolini. 2018. La comunità ornitica nidificante in un settore residuale della Campagna romana (corridoio tra le Riserve naturali 'Valle dei Casali' e 'Tenuta dei Massimi'; Roma, Italia centrale). Alula 25 (1-2): 1-9.

Biddle, L. E., R. E. Broughton, A. M. Goodman, and D. C. Deeming. 2018a. Composition of bird nests is a species-specific characteristic. Avian Biology Research 11 (2): 132-153.

Biddle, L. E., D. C. Deeming, and A. M. Goodman. 2018b. Birds use structural properties when selecting materials for different parts of their nests. Journal of Ornithology 159 (4): 999-1008.

Briggs, K. B., and D. C. Deeming. 2016. Use of materials in nest construction by Pied Flycatchers Ficedula hypoleuca reflects localized habitat and geographical location. Bird Study 63 (4): 516-524.

Cramp, S. (ed.) 1988. The birds of the Western Paleartic. Oxford: Oxford University Press.

Cramp, S., and C. M. Perrins. 1993. The birds of the western Palearctic. Vol. 7. Oxford: Oxford University Press.

Csada, R. D., and R. M. Brigham. 1994. Breeding biology of the common poorwill at the northern edge of its distribution. Journal of Field Ornithology 65 (2): 186-193.

Deeming, D. C. 2013. Effects of female body size and phylogeny in avian nest dimensions. Avian Biology Research 6: 1-11.

Deeming, D. C., and M. C. Mainwaring. 2015. Functional properties of nests. In Nests, eggs, and incubation: new ideas about avian reproduction, edited by Deeming, D. C. and S. J. Reynolds, 29-49. Oxford: Oxford University Press.

Deeming, C., L. Biddle, and C. du Feu. 2017. Interspecific and intraspecific spatial separation by birds breeding in nest boxes. Avian Conservation \& Ecology 12: 1-9.

Dytham, C. 2011. Choosing and using statistics: a biologist's guide. New York: John Wiley and Sons.

Erickson, C. J., and M. C. Martinez-Vargas. 1973. Some social and hormonal determinants of nest-building behaviour in the ring dove (Streptopelia risoria). Behaviour 45 (1-2): 12-36.

Fanelli G. 1998. Dasypyrum villosum vegetation in the territory of Rome. Rendiconti Lincei 9 (2): 149-170.

Fanelli, G., P. M. Bianco, P. Cazzagon, D. D’Angeli, M. De Sanctis, M. Bertarelli, V. Caroselli, S. De Corso, P. Gioia, A. Guerra, A. Serafini Sauli, A. Testi, and S. Pignatti. 2007. Banche dati vegetazionali della Provincia di Roma. Memoria illustrativa della carta della vegetazione della Provincia di Roma, Assessorato alle Politiche del Territorio, Roma, 128 pp.

Gelis, R. A., and F. Martinez. 2000. Nest and nestling description of Grey-collared Becard Pachyramphus major in the highlands of Michoacán, Mexico. Cotinga 14: $47-48$.

Goodall, A. L., D. Charles Deeming, and L. E. Biddle. 2019. Use of 'tree tin' nesting sites by the Eurasian Treecreeper Certhia familiaris, with notes on nest composition. Ringing \& Migration 34: 124-128.

Goodfellow, P. 2011. Avian Architecture: How Birds Design, Engineer and Build. Princeton, NJ: Princeton University Press.

Hammer, Ø., D. A. Harper, and P. D. Ryan. 2001. PAST: Paleontological statistics software package for education and data analysis. Palaeontologia electronica 4 (1): 9.

Hansell, M. 2000. Bird nests and construction behaviour. Cambridge:Cambridge University Press.

Harrap, S. 1996. Tits, nuthatches \& treecreepers. A\&C Black.

Hinkle, N. 2010. Animals: pets (companion animals) external parasite control. Georgia pest management handbook. Athens, USA: College of Agricultural and Environmental Sciences, University of Georgia. http:// www.ent.uga.edu/pmh

Howard, E. T. 1973. Properties of southern pine needles. Wood Science 5 (4): 281-286.

Jové-Sandoval, F., M. M. Barbero-Barrera, and N. F. Medina. 2018. Assessment of the mechanical performance of three varieties of pine needles as natural reinforcement of adobe. Construction and Building Materials 187: 205-213.

Kuitunen, M., and A. Aleknonis. 1992. Nest predation and breeding success in Common Treecreepers nesting in boxes and natural cavities. Ornis Fennica 69 (1): 7-12. Lambrechts, M. M., A. Charmantier, V. Demeyrier, A. Lu- 
cas, S. Perret, M. Abouladzé, M. Bonnet, C. Canonne, V. Faucon, S. Grosset, G. le Prado, F. Lidon, T. Noell, P. Pagano, V. Perret, S. Pouplard, R. Spitaliéry, C. Bernard, P. Perret, J. Blondel, A. Grégoire. 2017. Nest design in a changing world: great tit Parus major nests from a Mediterranean city environment as a case study. Urban Ecosystems 20: 1181-1190.

Lombardo, M. P., R. M. Bosman, C. A. Faro, S. G. Houtteman, and T. S. Kluisza. 1995. Effect of feathers as nest insulation on incubation behavior and reproductive performance of Tree Swallows (Tachycineta bicolor). The Auk 112 (4): 973-981.

Macchioni, F., P. L. Cioni, G. Flamini, I. Morelli, I. Maccioni, S. Maccioni, and M. Ansaldi. 2002. Chemical composition of essential oils from needles, branches and cones of Pinus pinea, $P$. halepensis, $P$. pinaster and . nigra from central Italy. Flavour and Fragrance Journal 18: 139-143.

Mainwaring, M. C. 2011. The use of nest boxes by roosting birds during the non-breeding season: a review of the costs and benefits. Ardea 99 (2): 167-176.

Mainwaring, M. C., I. R. Hartley, M. M. Lambrechts, and D. C. Deeming. 2014. The design and function of birds' nests. Ecology and Evolution 4 (20): 3909-3928.

Mascara, R., M. Sarà, and L. Zanca. 2011. Preliminary observation on use of nest boxes in protected areas of Southern Sicily. Natura Rerum 1: 61-66.

Merlino, S., M. Abbate, L. Pietrelli, P. Canepa, and P. Varella. 2018. Marine litter detection and correlation with the seabird nest content. Rendiconti Lincei. Scienze Fisiche e Naturali 29 (4): 867-875.

Navarro, F. A., E. J. Belda, and Y. L. Greño. 2010. Comparaciòn de los materiales utilizados en la costrucciòn del nido $\mathrm{y}$ de los paràmetros reproductores en el Chochìn Troglodytes troglodytes en la font roja y en La Serria de Mariola. Iberis 8: 17-22.

Newton, I. 1994. The role of nest sites in limiting the numbers of hole-nesting birds: a review. Biological Conservation 70: 265-276.

Pires, B. A., A. F. Belo, and J. E. Rabaça. 2012. Aromatic plants in Eurasian Blue Tit nests: the 'nest protection hypothesis' revisited. The Wilson Journal of Ornithology 124 (1): 162-165.

Quilodrán, C. S., R. A. Vásquez, and C. F. Estades. 2012. Nesting of the Thorn-tailed Rayadito (Aphrastura spinicauda) in a pine plantation in southcentral Chile. The Wilson Journal of Ornithology 124 (4): 737-742.

Reynolds, S. J., J. D. Ibáñez-Álamo, P. Sumasgutner, and M. C. Mainwaring. 2019. Urbanisation and nest building in birds: a review of threats and opportunities. Journal of Ornithology 160 (3): 841-860.

Robles, H., C. Ciudad, and E. Matthysen. 2012. Responses to experimental reduction and increase of cavities by a secondary cavity-nesting bird community in cavity-rich Pyrenean oak forests. Forest Ecology and Management 277: 46-53.

Snell, K. R. S., R. B. E. Jensen, T. E. Ortvad, M. Willemoes, and K. Thorup. 2020. Multiple fragmented habitat-patch use in an urban breeding passerine, the Short-toed Treecreeper. PLoS One 15 (1): e0227731.

Taberner Cerezo, A., and D. C. Deeming. 2016. Nest insulation in the European Robin (Erithacus rubecula): Effects of latitude and construction materials. Avian Biology Research 9: 96-102.

Tyler, W. M. 1914. Notes on Nest Life of the Brown Creeper in Massachusetts. The Auk 31: 50-62.

Winkler, D. W., and F. H. Sheldon. 1993. Evolution of nest construction in swallows (Hirundinidae): a molecular phylogenetic perspective. Proceedings of the National Academy of Sciences 90 (12): 5705-5707. 